\title{
Associations between indoor environmental smoke and respiratory symptoms among preschool children in Shanghai, China
}

\author{
LIU Wei ${ }^{1}$, HUANG Chen ${ }^{1 *}$, HU Yu ${ }^{1}$, ZOU ZhiJun ${ }^{1} \&$ SUNDELL Jan ${ }^{2}$ \\ ${ }^{1}$ School of Environment and Architecture, University of Shanghai for Science and Technology, Shanghai 200093, China; \\ ${ }^{2}$ Department of Building Science, Tsinghua University, Beijing 100084, China
}

Received November 23, 2012; accepted January 10, 2013; published online April 10, 2013

\begin{abstract}
Whether indoor environmental smoke is harmful for preschool children's respiratory health in a society where female smoking is rare has not been determined. This study is part of a cross-sectional study (CCHH study-phase one in Shanghai) and investigated associations between parental smoking and incense-burning and respiratory symptoms among 4-6 year old children in Shanghai, China. A number of 13335 valid questionnaires (response rate: $85.3 \%$ ) were analyzed. A number of $56.1 \%$ (as reported by a parent) of preschool children in Shanghai are exposed to environmental tobacco smoke (ETS). A number of $40.3 \%$ of fathers and $0.9 \%$ of mothers are smokers. A number of $53.7 \%$ and $12.6 \%$ of Shanghai residents have used mosquito-repellent incense and incensation respectively. Children exposed to any parental smoking have higher prevalence of wheeze and croup than those not exposed. Current maternal smoking has a significant and positive association with wheeze (in the last 12 months, AOR, 95\% CI: 1.83, 1.11-2.99). However, paternal smoking either currently or at child's birth had only weak associations with wheeze and croup. Incense-burning (mosquito-repellent incense and incensation) had significant and negative association with doctor-diagnosed asthma (AOR, 95\% CI: 0.85, 0.73-0.99) and hay fever (AOR, 95\% CI: 0.80, 0.70-0.93). The results indicate that maternal smoking perhaps is a stronger risk factor for children's respiratory health than paternal smoking.
\end{abstract}

environmental tobacco smoke, incense, asthma, wheeze, preschool children, Shanghai

Citation: Liu W, Huang C, Hu Y, et al. Associations between indoor environmental smoke and respiratory symptoms among preschool children in Shanghai, China. Chin Sci Bull, 2013, 58: 4211-4216, doi: 10.1007/s11434-013-5728-Z

It was estimated that worldwide, $40 \%$ of children were exposed to second hand smoke in 2004 [1]. Studies of environmental tobacco smoke (ETS) have found that it to be a risk factor for children's respiratory health in many developed countries or regions, for example in Italy [2], France [3], Portugal [4], Greece [5], Bulgaria [6], Singapore [7], Japan [8], USA [9-11] and Taiwan, China [12]. A study In Shanghai also found similar adverse effects from ETS [13]. Literature reviews have concluded that parental smoking is a risk factor for children's respiratory symptoms [14-20]. A review also found that effective tobacco smoke control can rapidly reduce the prevalence of respiratory diseases [21]. However, several studies found no association between parental smoking and asthma [22,23], wheeze [23,24], hay

*Corresponding author (email: huangc@usst.edu.cn, hcyhyywj@163.com) fever [24,25] or rhinitis [3,25]. Moreover, a study conducted by ISAAC Phase One Study Group, found that "countries that have high adult male smoking rates have a lower risk of asthma and rhinitis symptoms in children" [26].

Combustion of incensation and anti-mosquito incense are other resources of indoor environmental smoke. Their emissions of particle number (PM) are comparable to those of typical cooking activities [27-29]. Thus incense-burning may also be a risk for child's health [30-34]. However, one study has found indoor incense-burning is not associated with an increase in respiratory symptoms [34].

Therefore, epidemiologic evidence of associations between parental smoking exposure and incense-burning and children's respiratory health still need to be investigated. Nested in the China, Children, Homes, Health (CCHH) study, the present study aimed: (1) to evaluate exposure to 
ETS and other kinds of non-cooking smoke in the residences among 4-6 years old preschool children in Shanghai; (2) to compare the risk of ETS and other kinds of smoke for preschool children's respiratory symptoms and (3) to compare the risk of maternal and paternal smoking in an EastAsian society in which maternal smoking is rare.

\section{Methods}

\subsection{The survey}

The $\mathrm{CCHH}$ study has been conducted in Shanghai and other Chinese cities. The first phase is a cross-sectional study, and the second phase is a nested case-control study. $\mathrm{CCHH}$ is focused on the home environment and its impact on asthma, allergies and other respiratory symptoms among preschool children. From April 2011 to April 2012, the cross-sectional study (phase one) in Shanghai was conducted in 5 districts (out of 18) by questionnaires. In total, 72 kindergartens were randomly selected in those districts and Parents of 17898 children were surveyed. Questionnaires were distributed by two methods: (1) delivered to parents and recovered on-site by us in kindergartens at the teacher-parents meetings, and (2) posted to kindergartens where teachers delivered them to parents, and then recovered them and mailed them back to us. The Shanghai Municipal Bureau of Education had agreed with the survey questionnaire and methods of its distribution and collection.

\subsection{The questionnaire and statistical analysis}

Questions on children's respiratory symptoms were the same as in the International Study of Asthma and Allergies in Childhood (ISAAC) [35]. Questions on parental smoking were similar to those used in the Dampness in Building and
Health (DBH) study in Sweden [36] and the ALLHOME study in Bulgaria [6]. Questions about incense (Table 1) were added according to Chinese living customs. Pictures of tobacco smoke mosquito-repellent incense and incensation which were involved in the survey were showed in Figure 1.

The data were input and analyzed by SPSS version 17.0 (SPSS Ltd., Chicago, Illinois, USA). All of the analyses were restricted to individuals with all complete data for the variables required in a particular analysis. Due to missing data for various items, the sums of children with different symptoms or different exposures in subgroups are not necessarily equal to the total numbers. Pearson Chi-Square Test (2-tailed) was used to analyze the statistical significance of differences between prevalences in different groups. Multiple logistic regression analysis was applied to further investigate associations, which were indicated in adjusted odds ratio (AOR) with a $95 \%$ confidence interval $(95 \% \mathrm{CI})$. Statistical significance was indicated by $P \leqslant 0.05$. All analyses of associations between family (parental) smoking and incense-burning and respiratory symptoms were adjusted for age ( $\leqslant 4$ years old vs. $>4$ years old); sex; location of kindergartens (urban area vs. suburb); family history of asthma or allergies; Sick Building Syndrome (SBS), defined as producing at least one of following symptoms: fatigue, feeling heavy-headed, headache, nausea/dizziness, difficulties concentrating, itching or burning or irritation of the eyes, irritated or stuffy or runny nose, hoarse or dry throat, cough, dry or flushed facial shin, scurf or itching scalp or ears, dry hands, itching or red skin, and joint pain; among those families who filled out the questionnaire (yes vs. no); who filled out the questionnaire (mother vs. not mother); early furred pet- keeping; dampness (visible mould and/or visible damp stains on the floor, walls or ceiling in the child's room: yes vs. no); ownerships of current residence; breastfeeding $(\leqslant 6$ months vs. $>6$ months).

Table 1 Questions and answers about indoor ETS exposure and incense-burning in the questionnaire

\begin{tabular}{lll}
\hline \multicolumn{1}{c}{ Items } & \multicolumn{1}{c}{ Question } & \multicolumn{1}{c}{ Answer } \\
\hline $\begin{array}{l}\text { Environmental tobacco } \\
\text { smoke }\end{array}$ & Does anyone smoke in your family currently? & Mother vs. father vs. grandmother vs. grandfather vs. none \\
& Did father or mother smoke during the first year of child's life? & Mother vs. father vs. none \\
& Did father or mother smoke during pregnancy? & Mother vs. father vs. none \\
Incense-burning ever & How often do you use mosquito-repellent incense at home? & Yes vs. no \\
& How often do you use incensation at home? & Yes vs. no \\
\hline
\end{tabular}
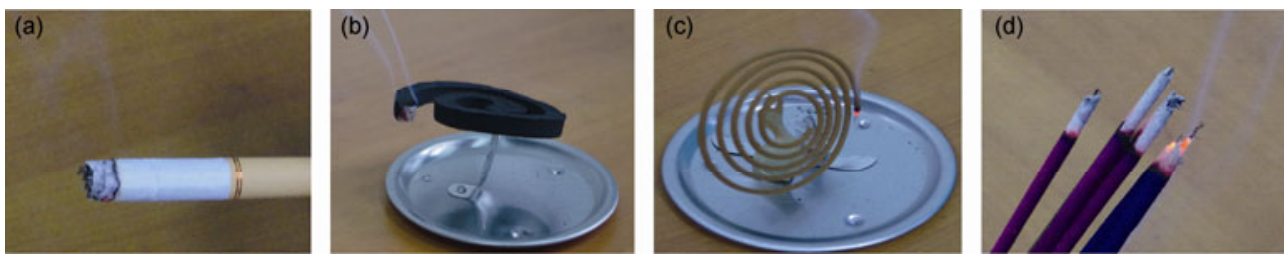

Figure 1 Illustration of sources of environmental smoke producers in the residence. (a) Tobacco smoking; (b) mosquito-repellent incense; (c), (d) incensation. Herein the incensation included the incense (c) used for changing indoor odors, or changing the odors of the clothing, and the incense (d) which is commonly used in Chinese temples for religious purposes. 


\section{Results}

A number of 15266 valid questionnaires (response rate: $85.3 \%$ ) of children aged from 1 to 8 years old were returned. 13335 children, aged " 4 years old" $(41.7 \%)$, "5 years old" $(33.0 \%)$ and "6 years old" $(25.3 \%)$, were selected for further analyses.

Totally, $56.1 \%$ of preschool children in Shanghai are reported to have ETS-exposure currently. Most of smokers are fathers, and maternal smoking is rare (Table 2). There is more paternal smoking in suburban than urban areas, while maternal smoking is the reverse. Those who own their current house smoke/smoked less than those who do not. Those with a family history of asthma or allergies smoke/smoked less than those without. Moreover, $53.7 \%$ and $12.6 \%$ of Shanghai inhabitants have used mosquito-repellent incense and incensation respectively (Table 2). Suburban residents or those who did not own their current homes used more mosquito-repellent incense and incensation than urban residents or those who owned their current residence respectively. Residents with a family history of asthma or allergies used less mosquito-repellent incense but used more incensation than those without.

The prevalences of respiratory symptoms among 4-6 years old preschool children exposed to different indoor environmental smokes are shown in Table 3. The prevalence of rhinitis symptoms in the last 12 months, doctor-diagnosed asthma and hay-fever are significantly lower among those children in families who have used mosquito-repellant incense or incensation. However, most of differences between the prevalence of children with family (parental) smoking and the prevalence of those without family (parental) smoking are small and not statistically significant, except for wheeze ever (parental smoking during pregnancy or

Table 2 Percentages of parental smoking and incense-burning in the residence

\begin{tabular}{|c|c|c|c|c|c|c|c|c|c|c|c|c|c|}
\hline & \multicolumn{4}{|c|}{ Family smoking currently } & \multicolumn{3}{|c|}{ Parental smoking at birth } & \multicolumn{3}{|c|}{ Parental smoking, pregnancy } & \multicolumn{2}{|c|}{ Incense-burning ever } \\
\hline & & Total & Father & Mother & $\mathrm{GP}^{\text {a) }}$ & Total & Father & Mother & Total & Father & Mother & Mosquito-repellent & Incensation \\
\hline \multirow{2}{*}{ Total } & $n$ & 7205 & 5216 & 123 & 3438 & 5444 & 5354 & 120 & 5115 & 5032 & 103 & 5991 & 1554 \\
\hline & $\%$ & 56.1 & 40.3 & 0.9 & 26.5 & 41.6 & 40.7 & 0.9 & 39.1 & 38.3 & 0.8 & 53.7 & 12.6 \\
\hline \multicolumn{14}{|c|}{ The location of the kindergartens } \\
\hline \multicolumn{2}{|c|}{ Urban } & $53.1^{\mathrm{d})}$ & $38.5^{\text {d) }}$ & 1.1 & $24.3^{\text {d) }}$ & 40.8 & $39.7^{\mathrm{c})}$ & $1.5^{\mathrm{d})}$ & 38.3 & $37.4^{\mathrm{c})}$ & $1.2^{\mathrm{d})}$ & $52.9^{\mathrm{d})}$ & 12.4 \\
\hline \multicolumn{2}{|c|}{ Suburban } & 58.9 & 42.6 & 0.8 & 29.4 & 42.1 & 42.0 & 0.2 & 39.8 & 39.6 & 0.2 & 37.8 & 12.8 \\
\hline Y & & $52.6^{\mathrm{d})}$ & $36.8^{\text {d) }}$ & $0.7^{\mathrm{c})}$ & 26.2 & $38.4^{\text {d) }}$ & $37.8^{\text {d) }}$ & 0.8 & $36.3^{\text {d) }}$ & $35.7^{\text {d) }}$ & 0.8 & $47.8^{\text {d) }}$ & 12.3 \\
\hline & & 60.8 & 46.1 & 1.3 & 27.2 & 46.3 & 45.5 & 1.0 & 43.5 & 42.8 & 0.8 & 63.7 & 13.2 \\
\hline \multicolumn{14}{|c|}{ Does the family member have asthma or allergies? } \\
\hline & & $53.5^{\mathrm{c})}$ & $37.4^{\text {d) }}$ & 0.6 & 27.6 & $39.2^{\mathrm{b})}$ & $38.7^{\mathrm{b})}$ & 0.9 & $37.3^{\text {b) }}$ & 36.9 & 0.8 & $49.8^{\text {d) }}$ & $14.3^{\text {d) }}$ \\
\hline & & 56.2 & 41.0 & 1.0 & 26.2 & 41.9 & 41.2 & 0.9 & 39.3 & 38.6 & 0.8 & 54.9 & 12.0 \\
\hline
\end{tabular}

a) Grandparents, either grandmothers or grandfathers; b) $0.01<P \leqslant 0.05$; c) $0.001<P \leqslant 0.01$; d) $P \leqslant 0.001$.

Table 3 The prevalence of respiratory symptoms among 4-6 years old children with exposure to different no-cooking types of smoking a)

\begin{tabular}{|c|c|c|c|c|c|c|c|c|c|c|c|c|c|c|c|c|c|c|}
\hline \multirow[t]{2}{*}{ Symptoms } & \multicolumn{2}{|c|}{$\begin{array}{c}\text { Wheeze } \\
\text { ever }\end{array}$} & \multicolumn{2}{|c|}{$\begin{array}{c}\text { Wheeze } \\
\text { last } 12 \text { months }{ }^{\text {b) }} \\
\end{array}$} & \multicolumn{2}{|c|}{$\begin{array}{c}\text { Dry cough } \\
\text { during night }^{c)}\end{array}$} & \multicolumn{2}{|c|}{$\begin{array}{c}\text { Asthma } \\
\text { doctor-diagnosed }\end{array}$} & \multicolumn{2}{|c|}{$\begin{array}{l}\text { Croup } \\
\text { ever }\end{array}$} & \multicolumn{2}{|c|}{$\begin{array}{c}\text { Pneumonia } \\
\text { ever }\end{array}$} & \multicolumn{2}{|c|}{$\begin{array}{c}\text { Rhinitis } \\
\text { ever }\end{array}$} & \multicolumn{2}{|c|}{$\begin{array}{c}\text { Rhinitis } \\
\text { last } 12 \text { months } \\
\end{array}$} & \multicolumn{2}{|c|}{$\begin{array}{c}\text { Hay fever } \\
\text { doctor-diagnosed }\end{array}$} \\
\hline & $n$ & $\%$ & $n$ & $\%$ & $n$ & $\%$ & $n$ & $\%$ & $n$ & $\%$ & $n$ & $\%$ & $n$ & $\%$ & $n$ & $\%$ & $n$ & $\%$ \\
\hline Total & 3722 & 28.3 & 2858 & 21.7 & 2569 & 19.5 & 1342 & 10.3 & 963 & 7.6 & 4335 & 33.6 & 7076 & 54.1 & 5532 & 42.7 & 1624 & 12.6 \\
\hline \multicolumn{19}{|c|}{ Family smoking Currently? } \\
\hline Yes & 2050 & 28.9 & 1587 & $22.4^{\text {d) }}$ & 1391 & 19.5 & 729 & 10.4 & 545 & 7.9 & 2337 & 33.5 & 3801 & 53.8 & 2985 & 42.5 & 883 & 12.7 \\
\hline No & 1564 & 27.5 & 1191 & 20.9 & 1114 & 19.5 & 571 & 10.2 & 384 & 7.2 & 1878 & 33.7 & 3059 & 54.1 & 2394 & 42.8 & 703 & 12.5 \\
\hline \multicolumn{19}{|c|}{ Parental smoking during the first year of child's life? } \\
\hline Yes & 1572 & $29.4^{\text {d) }}$ & 1203 & 22.4 & 1052 & 19.5 & 568 & 10.7 & 425 & $8.2^{\text {d) }}$ & 1791 & 34.1 & 2875 & 53.8 & 2237 & 42.2 & 667 & 12.6 \\
\hline No & 2093 & 27.4 & 1608 & 21.1 & 1489 & 19.5 & 751 & 10.0 & 528 & 7.1 & 2495 & 33.4 & 4106 & 54.2 & 3230 & 43.0 & 933 & 12.4 \\
\hline \multicolumn{19}{|c|}{ Parental smoking during pregnancy? } \\
\hline Yes & 1472 & $29.3^{\text {d) }}$ & 1125 & 22.3 & 1005 & 19.9 & 539 & 10.8 & 392 & 8.1 & 1693 & 34.3 & 2694 & 53.6 & 2111 & 42.3 & 625 & 12.6 \\
\hline No & 2186 & 27.6 & 1679 & 21.2 & 1531 & 19.2 & 775 & 9.9 & 555 & 7.2 & 2587 & 33.3 & 4272 & 54.3 & 3342 & 42.9 & 973 & 12.5 \\
\hline \multicolumn{19}{|c|}{ Whether used mosquito-repellent incense ever? } \\
\hline Yes & 1647 & 27.9 & 1265 & 21.4 & 1143 & 19.3 & 521 & $9.0^{f)}$ & 423 & 7.4 & 1906 & 33.0 & 3113 & 52.9 & 2386 & $41.0^{\mathrm{d})}$ & 623 & $10.7^{f)}$ \\
\hline \multicolumn{19}{|c|}{ Whether used incensation ever? } \\
\hline Yes & 460 & 30.0 & 370 & $24.0^{\mathrm{d})}$ & 338 & $21.9^{\mathrm{e})}$ & 139 & 9.3 & 125 & 8.5 & 445 & 32.9 & 896 & $58.5^{\mathrm{f})}$ & 692 & $45.9^{\mathrm{e})}$ & 164 & $11.0^{\mathrm{d})}$ \\
\hline No & 3002 & 28.1 & 2290 & 21.4 & 2053 & 19.2 & 1116 & 10.6 & 767 & 7.4 & 3554 & 33.9 & 5664 & 53.3 & 4443 & 42.2 & 1353 & 12.9 \\
\hline
\end{tabular}

a) "\%" are prevalence, and " $n$ " are the diseased children's numbers; b) in the last 12 months; c) in the last 12 months, the child had dry cough at night for more than two weeks, apart from a cough associated with a cold or chest infection; d) $0.01<P \leqslant 0.05 ;$ e) $0.001<P \leqslant 0.01$; $) P \leqslant 0.001$. 
in first year of child's life), croup ever (parental smoking during first year of life), and rhinitis in last 12 months (family smoking currently).

Adjusted associations between family (parental) smoking during different times and incense burning and children's illnesses and symptoms are shown in Table 4. Family smoking currently and parental smoking either at child's birth or during pregnancy were significant risk factors for wheeze. However, incense-burning ever was significantly and negatively associated with doctor-diagnosed asthma (AOR, 95\% CI: 0.85, 0.73-0.99) and hay fever (AOR, 95\% CI: 0.80, 0.70-0.93). The risks of paternal smoking and maternal smoking during different durations are compared in Table 5. Paternal smoking either currently or at child's birth was a significant risk factor for croup and wheeze in the last 12 months. Current maternal smoking seemingly had stronger associations with children's symptoms than paternal smoking, but was significant only for wheeze in the last 12 months.

\section{Discussion}

Currently, 56.1\% of preschool children in Shanghai are exposed to household ETS. The rate of paternal smoking (40.3\%) is comparable to that in many countries or regions. The percentages of maternal smoking $(0.9 \%)$ in families with 4-6 years old children in Shanghai were much smaller than those in western countries, but similar to those in other Asian countries. For example, in Bulgaria, $72.9 \%$ of the families had at least one of family member who smoked, and $47.9 \%$ of mothers were smokers [6]. In the Czech Republic, " $35.6 \%$ of the mothers and $48.9 \%$ of their husbands or partners were smokers" and $58.4 \%$ of children were exposed to ETS [37]. In Portugal, the rates of maternal and paternal smoking were $32.0 \%$ and $38.0 \%$ respectively, and household ETS was present in 41\% [4]. About half of German 3-14 years old children were exposed to ETS in their homes [38]. But among one year old infants in Thailand, only $0.3 \%$ of the mothers and $35.1 \%$ of the fathers were

Table 4 Logistic regression analysis of indoor ETS exposure in different times and incense-burning ever

\begin{tabular}{|c|c|c|c|c|c|c|}
\hline \multirow[b]{2}{*}{$\begin{array}{l}\mathrm{AOR}, 95 \% \mathrm{CI} \\
(n / N)^{\mathrm{c})}\end{array}$} & \multicolumn{3}{|c|}{ Family (parental) smoking (none smoking $=1.00$ ) } & \multicolumn{3}{|c|}{ Incense-burning ever (never using incense $=1.00$ ) } \\
\hline & $\begin{array}{c}\text { Currently }^{\text {a) }} \\
(7205 / 12840)\end{array}$ & $\begin{array}{l}\text { At child's birth }{ }^{\text {b) }} \\
(5444 / 13157)\end{array}$ & $\begin{array}{l}\left.\text { Pregnancy }^{b}\right) \\
(5115 / 13132)\end{array}$ & $\begin{array}{c}\text { Overall } \\
(6695 / 11148)\end{array}$ & $\begin{array}{c}\text { Mosquito-repellent } \\
(5991 / 11150)\end{array}$ & $\begin{array}{c}\text { Incensation } \\
(1554 / 12355)\end{array}$ \\
\hline Wheeze, ever & $1.11,1.01-1.23^{c)}$ & $1.15,1.04-1.26^{\mathrm{d})}$ & $1.11,1.01-1.22^{\mathrm{c})}$ & $0.98,0.89-1.09$ & $1.01,0.91-1.11$ & $0.99,0.86-1.14$ \\
\hline Wheeze, in the last 12 months & $1.13,1.01-1.25^{\mathrm{c})}$ & $1.13,1.01-1.25^{\mathrm{c})}$ & $1.01,0.99-1.22$ & $0.98,0.88-1.10$ & $1.02,0.91-1.14$ & $1.00,0.86-1.17$ \\
\hline Dry cough, during nights & $1.03,0.93-1.15$ & $1.06,0.95-1.17$ & $1.08,0.97-1.20$ & $1.15,1.03-1.29^{\mathrm{c})}$ & $1.10,0.98-1.23$ & $1.15,0.98-1.34$ \\
\hline Croup, ever & $1.15,0.98-1.36$ & $1.23,1.04-1.44^{\mathrm{c})}$ & $1.15,0.98-1.36$ & $1.13,0.94-1.35$ & $1.08,0.90-1.28$ & $1.12,0.88-1.41$ \\
\hline Pneumonia, ever & $1.00,0.91-1.09$ & $1.02,0.94-1.12$ & $1.03,0.94-1.13$ & $0.96,0.87-1.06$ & $0.96,0.87-1.06$ & $0.95,0.83-1.09$ \\
\hline Rhinitis, ever & $0.99,0.91-1.08$ & $0.98,0.90-1.07$ & $0.98,0.90-1.07$ & $1.09,0.99-1.19$ & $1.05,0.96-1.15$ & $1.09,0.95-1.24$ \\
\hline Rhinitis, in the last 12 months & $1.03,0.94-1.12$ & $1.01,0.93-1.11$ & $1.02,0.94-1.12$ & $1.05,0.95-1.15$ & $1.02,0.93-1.12$ & $1.01,0.89-1.16$ \\
\hline Hay fever, doctor-diagnosed & $1.08,0.94-1.23$ & $1.13,0.99-1.29$ & $1.13,0.99-1.29$ & $0.80,0.70-0.93^{\mathrm{d})}$ & $0.86,0.75-1.00^{\mathrm{c})}$ & $0.70,0.56-0.86^{\mathrm{e})}$ \\
\hline
\end{tabular}

a) At least one of family members (father, mother, grandfather, and grandmother) smoke in the residence currently; b) at least one of parent (father and mother) smoked in the residence at child's birth; " $n$ " are the amounts of families with smoking or burning incense in different groups, and " $N$ " are the total valid amounts of different groups; c) $0.01<P \leqslant 0.05$; d) $0.001<P \leqslant 0.01$; e) $P \leqslant 0.001$.

Table 5 Logistic regression analysis of the risk of paternal smoking and maternal smoking at different times

\begin{tabular}{|c|c|c|c|c|c|c|}
\hline \multirow{2}{*}{$\begin{array}{c}\mathrm{AOR}, 95 \% \mathrm{CI} \\
(\text { none smoker }=1.00)\end{array}$} & \multicolumn{2}{|c|}{ Currently } & \multicolumn{2}{|c|}{ At child's birth } & \multicolumn{2}{|c|}{ During pregnancy } \\
\hline & Fathers $(n=3651)^{\mathrm{a})}$ & Mothers $(n=123)$ & Fathers $(n=5323)^{\mathrm{b})}$ & Mothers $(n=120)$ & Fathers $(n=5011)^{\mathrm{b})}$ & Mothers $(n=103)$ \\
\hline Wheeze, ever & $1.14,1.02-1.28^{\mathrm{c})}$ & $1.59,0.99-2.57$ & $1.14,1.04-1.26^{\mathrm{d})}$ & $1.53,0.95-2.46$ & $1.11,1.01-1.22^{\mathrm{c})}$ & $1.21,0.70-2.10$ \\
\hline Wheeze, in the last 12 months & $1.16,1.03-1.32^{\mathrm{c})}$ & $1.83,1.11-2.99^{\mathrm{c})}$ & $1.12,1.01-1.24^{\mathrm{c})}$ & $1.38,0.82-2.33$ & $1.11,0.99-1.23$ & $0.81,0.41-1.58$ \\
\hline Dry cough, during nights & $1.03,0.90-1.17$ & $1.42,0.83-2.40$ & $1.06,0.95-1.18$ & $0.89,0.50-1.60$ & $1.08,0.97-1.20$ & $0.92,0.49-1.76$ \\
\hline Asthma, doctor-diagnosed & $1.21,1.02-1.43^{\mathrm{c})}$ & $1.30,0.63-2.68$ & $1.13,0.98-1.30$ & $1.53,0.80-2.92$ & $1.14,0.99-1.32$ & $1.25,0.58-2.70$ \\
\hline Pneumonia, ever & $1.01,0.91-1.13$ & $0.83,0.50-1.38$ & $1.02,0.93-1.12$ & $1.12,0.70-1.80$ & $1.03,0.94-1.13$ & $0.94,0.55-1.60$ \\
\hline Rhinitis, ever & $0.91,0.82-1.00$ & $1.29,0.80-2.09$ & $0.99,0.91-1.08$ & $0.76,0.48-1.20$ & $0.99,0.91-1.08$ & $0.61,0.37-1.02$ \\
\hline Rhinitis, in the last 12 months & $0.95,0.85-1.05$ & $1.03,0.64-1.65$ & $1.01,0.93-1.11$ & $0.99,0.63-1.58$ & $1.03,0.94-1.12$ & $0.84,0.50-1.42$ \\
\hline Hay fever, doctor-diagnosed & $1.09,0.93-1.28$ & $1.60,0.82-3.11$ & $1.14,0.99-1.30$ & $0.85,0.41-1.77$ & $1.13,0.99-1.29$ & $0.98,0.45-2.14$ \\
\hline
\end{tabular}

a) To eliminate the confounding from GP smoking and maternal smoking, only these families with sole fathers smoking were selected; b) to eliminate the confounding from maternal smoking, only these families with sole fathers smoking were selected; c) $0.01<P \leqslant 0.05 ; \mathrm{d}) 0.001<P \leqslant 0.01$. 
smokers [39]. In Japan [8] and South Korea [40], 43.9\% and $50.9 \%$ of children were exposed to ETS at home at the time of the survey. In Singapore, $13.2 \%$ of children were exposed to parental smoking [7]. In Taiwan, China, $44.9 \%$ of children had current household ETS exposure, and $36.0 \%$ of fathers and $3.4 \%$ of mothers are smokers [12]. In our study, the rate of paternal smoking was higher in suburban than in urban areas, but the reverse was found for maternal smoking, consistent with the findings of other studies $[4,41]$ in western countries.

Most of the associations between family (mainly parental) smoking and children's health in the present study are not significant. Although many studies have found in utero exposure to ETS have significant associations with asthma and wheeze $[3,9,10,12]$, our results in Table 4 indicated there are no significant associations between ETS exposure during pregnancy and children's symptoms except wheeze. Several studies [2-8,11-13,41] and reviews [14-20] also have concluded that childhood ETS exposure has significant associations with lifetime wheeze and asthma. We only found that family smoking either currently or at child's birth has weak associations with child's wheeze ever or in the last 12 months (Table 4). We also found no significant associations between parental smoking (both paternal and maternal smoking) and child's rhinitis and hay fever, which are consistent with previous studies $[3,24,25]$. Therefore, smoking among parents may be not a strong risk factor for respiratory symptoms. When we conducted the questionnaires, parents with family smokers have told us that these smokers avoid smoking in the presence of children. Moreover, some other studies found that maternal smoking is a greater risk than paternal smoking for child's current wheeze $[2,26]$ and asthma [41]. We have found similar results (Table 5). Thus, maternal smoking seemingly is a stronger risk factor for children's asthmatic symptoms than paternal smoking. But it's still need to be further verified, and more accurately quantitative measure about indoor ETS exposure also should be explored.

In Asian countries, incense-burning, including mosquitorepellent incense and incensation, is an important source of indoor environmental smoke [30,34]. Several studies have investigated the characteristics of burning incense's emission [27-31] and their associations with health [31-34]. The smoldering combustion of both anti-mosquito products and incensation emit comparable particle numbers and size fractions to typical cooking activities [27] or other indoor sources of smoke [28]. Liao et al. [30] found the major contributors of indoor 1-5 $\mu \mathrm{m}$ particles to be cooking and incense burning activities. Liu et al. [31] found that burning one mosquito coil would produce the same amount of $\mathrm{PM}_{2.5}$ mass as burning 75-137 cigarettes, and the same quantity of formaldehyde as 51 cigarettes. Using questionnaire assessment, Wang et al. [33] found that incense burning has significant positive associations with current asthma and wheeze. However, Koo et al. [34] found no associations between incense-burning exposure and respiratory symptoms (wheeze, asthma, rhinitis and pneumonia). The results in Table 4 are partly consistent with Koo et al.'s findings [34]. But we found that incense-burning was a significant protective factor for doctor-diagnosed asthma and hay fever, although different kinds of incense may emit different particle numbers and size fractions [27-29]. Thus the associations between different kinds of incense-burning and children's symptoms are not clear and need further investigations.

The present study has some limitations. Firstly, maternal smoking was so rare as to weaken the statistical significance of associations (Tables 4 and 5). Secondly, parental avoidance behavior for smoking and incense-burning were not directly asked about. Thus we can not exactly analyze that how much those associations are influenced by these avoidance behavior. Finally, other factors, such as how often, what kind of incense were burned in the residence, ventilation during incense burning and the daily amount of parental smoking, were not analyzed in this study and need to be further investigated.

Nonetheless, the present study has several strengths. The sample was large, and the response rate was high. The data therefore are likely representative for Shanghai's 4-6 year old children and their various home situations. The large sample size means that potential confounders, such as age, sex, family history of asthma or allergies and geographical background, can be properly adjusted for. Moreover, an internationally standardized questionnaire of symptoms [35] and on environmental factors $[6,7,11,12,36]$ was used. Thus, results could be reliably compared to those of many other similar studies, and could reveal the associations between parental smoking and incense-burning and preschool children's respiratory symptoms to a certain extent in Shanghai City.

\section{Conclusions}

The rate of paternal smoking among Shanghai preschool children is comparable to that in many countries, while the low rate of maternal smoking (about 1.0\%) is comparable to that of other Asian countries, but not western countries. Maternal smoking may be a stronger risk factor for children's respiratory health than paternal smoking. The associations between mosquito-repellent incense or incensation and children's symptoms are not clear.

This work was supported by the Leading Academic Discipline Project of Shanghai Municipal Education Commission (J50502) and the National Natural Science Foundation of China (51108263 and 51278302). The authors greatly appreciate the Shanghai Municipal and District Bureau of Education for their supports. Thank you to all the parents, the kindergartens' teachers and others who involved in our survey. And a special thank you to Louise B. Weschler for helping with the English language and to Yuexia Sun (Tianjin University) for guidance of the cross-sectional study and questionnaire. 
1 Öerg M, Jaakkola M S, Woodward A, et al. Worldwide burden of disease from exposure to second-hand smoke: A retrospective analysis of data from 192 countries. Lancet, 2011, 377: 139-146

2 Pirastu R, Bellu C, Greco P, et al. Indoor exposure to environmental tobacco smoke and dampness: Respiratory symptoms in Sardinian children-DRIAS study. Environ Res, 2009, 109: 59-65

3 Raherisona C, Pénard-Morand C, Moreau D, et al. In utero and childhood exposure to parental tobacco smoke, and allergies in schoolchildren. Respir Med, 2007, 101: 107-117

4 Constant C, Sampaio I, Negreiro F, et al. Environmental tobacco smoke (ETS) exposure and respiratory morbidity in school age children. Rev Port Pneumol, 2011, 17: 20-26

5 Xepapadaki P, Manios Y, Liarigkovinos T, et al. Association of passive exposure of pregnant women to environmental tobacco smoke with asthma symptoms in children. Pediatr Allergy Immunol, 2009, 20: 423-429

6 Naydenov K G. On the association between home exposure and asthma and allergies among children in Bulgaria/The ALLHOME Study/. Doctoral Dissertation. Lyngby: Technical University of Denmark and ICIEE, 2007

7 Zuraimi M S, Tham K W, Chew F T, et al. Home exposures to environmental tobacco smoke and allergic symptoms among young children in Singapore. Int Arch Allergy Immunol, 2008, 146: 57-65

8 Tanaka K, Miyake Y, Arakawa M, et al. Prevalence of asthma and wheeze in relation to passive smoking in Japanese children. Ann Epidemiol, 2007, 17: 1004-1010

9 Gilliland F D, Li Y F, Peters J M. Effects of Maternal smoking during pregnancy and environmental tobacco smoke on asthma and wheezing in children. Am J Respir Crit Care Med, 2001, 163: 429436

10 Gilliland F D, Li Y F, Dubeau L, et al. Effects of glutathione $\mathrm{s}$-transferase $\mathrm{m} 1$, maternal smoking during pregnancy, and environmental tobacco smoke on asthma and wheezing in children. Am J Respir Crit Care Med, 2002, 166: 457-463

11 Sun Y X, Sundell J. Life style and home environment are associated with racial disparities of asthma and allergy in Northeast Texas children. Sci Total Environ, 2011, 409: 4229-4234

12 Tsai C H, Huang J H, Hwang B F, et al. Household environmental tobacco smoke and risks of asthma, wheeze and bronchitic symptoms among children in Taiwan. Respir Res, 2010, 11: 11-20

13 Wu J G, Zhuang Z J, Niu C J, et al. A case-control study on risk factors of asthma among 4-15 years school-aged children in a district of Shanghai (in Chinese). J Environ Occup Med, 2010, 27: 193-197

14 Jaakkola J J K, Jaakkola M S. Effects of environmental tobacco smoke on the respiratory health of children. Scand J Work Environ Health, 2002, 28(Suppl 2): 71-83

15 Gold D R. Environmental tobacco smoke, indoor allergens, and childhood asthma. Environ Health Perspect, 2000, 108(Suppl 4): 643-651

16 Gergen P J. Environmental tobacco smoke as a risk factor for respiratory disease in children. Respir Physiol, 2001, 128: 39-46

17 Peat J K, Keena V, Harakeh Z, et al. Parental smoking and respiratory tract infections in children. Paediatr Respir Rev, 2001, 2: 207213

18 Landau L I. Parental smoking: Asthma and wheezing illnesses in infants and children. Paediatr Respir Rev, 2001, 2: 202-206

19 Difranza J R, Aligne C A, Weitzman M. Prenatal and postnatal environmental tobacco smoke exposure and children's health. Pediatrics, 2004, 113: 1007-1015

20 Henderson A J. The effects of tobacco smoke exposure on respiratory health in school-aged children. Paediatr Respir Rev, 2008, 9: 21-28

21 Glantz S, Gonzalez M. Effective tobacco control is key to rapid pro- gress in reduction of non-communicable diseases. Lancet, 2011, 379: 1269-1271

22 Magnusson L L, Olesenz A B, Wennborg H, et al. Wheezing, asthma, hay fever, and atopic eczema in childhood following exposure to tobacco smoke in fetal life. Clin Exp Allergy, 2005, 35: 1550-1556

23 Zlotkowska R, Zejda J E. Fetal and postnatal exposure to tobacco smoke and respiratory health in children. Eur J Epidemiol, 2005, 20: 719-727

24 Krämer U, Lemmen $\mathrm{C} \mathrm{H}$, Behrendt $\mathrm{H}$, et al. The effect of environmental tobacco smoke on eczema and allergic sensitization in children. British J Dermatology, 2004, 150: 111-118

25 Montefort S, Muscat H A, Caruana S, et al. Allergic conditions in 5-8-year-old Maltese schoolchildren: Prevalence, severity, and associated risk factors [ISAAC]. Pediatr Allergy Immunol, 2002, 13: 98104

26 Mitchell E A, Stewart A W. The ecological relationship of tobacco smoking to the prevalence of symptoms of asthma and other atopic diseases in children: The International Study of Asthma and Allergies in Childhood (ISAAC). Eur J Epidemiol, 2001, 7: 667-673

27 Stabile L, Fuoco F C, Buonanno G. Characteristics of particles and black carbon emitted by combustion of incenses, candles and antimosquito products. Build Environ, 2012, 56: 184-191

28 Jetter J J, Guo Z S, Mcbrian J A, et al. Characterization of emissions from burning incense. Sci Total Environ, 2002, 295: 51-67

29 Wang B, Lee S C. Characteristics of emissions of air pollutants from mosquito coils and candles burning in a large environmental chamber. Atmos Environ, 2006, 40: 2128-2138

30 Liao C M, Chen S C, Chen J W, et al. Contributions of Chinese-style cooking and incense burning to personal exposure and residential PM concentrations in Taiwan region. Sci Total Environ, 2006, 358: 7284

31 Liu W L, Zhang J F, Hashim J H, et al. Mosquito coil emissions and health implications. Environ Health Perspect, 2003, 111: 1454-1460

32 Chen S C, Wong R H, Shiu L J, et al. Exposure to mosquito coil smoke may be a risk factor for lung cancer in Taiwan. J Epidemiol, 2008, 18: 19-25

33 Wang I J, Tsai C H, Chen C H, et al. Glutathione S-transferase, incense burning and asthma in children. Eur Respir J, 2011, 37: 13711377

34 Koo L C, Ho J H C, Tominaga S, et al. Is Chinese incense smoke hazardous to respiratory health? Epidemiological results from Hong Kong. Indoor Environ, 1995, 4: 334-343

35 Asher M I, Keil U, Anderson H R. International study of asthma and allergies in childhood (ISAAC): Rationale and methods. Eur Respir J, 1995, 8: 483-491

36 Engman L H. Indoor environmental factors and its associations with asthma and allergy among Swedish pre-school children. Doctoral Dissertation. Lund: Lund University, 2006

37 Dostál M, Milcová A, Binkoá B, et al. Environmental tobacco smoke exposure in children in two districts of the Czech Republic. Int J Hyg Environ Health, 2008, 211: 318-325

38 Conrad A, Schulz C, Seiwert M, et al. German environmental survey IV: Children's exposure to environmental tobacco smoke. Toxic Lett, 2010, 192: 79-83

39 Wanaporn A, Ladda M, Arinda M, et al. Prevalence and associated factors of passive smoking in Thai infants. Respir Med, 2008, 47: 443-446

40 Yi O, Kwon $\mathrm{H} \mathrm{J}$, Kim H, et al. Effect of environmental tobacco smoke on atopic dermatitis among children in Korea. Environ Res, 2012, 113: 40-45

41 Agabiti N, Mallone S, Forastiere F, et al. The impact of parental smoking on asthma and wheezing. Epidemiology, 1999, 10: 692-698

Open Access This article is distributed under the terms of the Creative Commons Attribution License which permits any use, distribution, and reproduction in any medium, provided the original author(s) and source are credited. 